\title{
Cardiopulmonary Exercise Testing in Athletes; a case-based review
}

\section{EXERCISE IS MEDICINE}

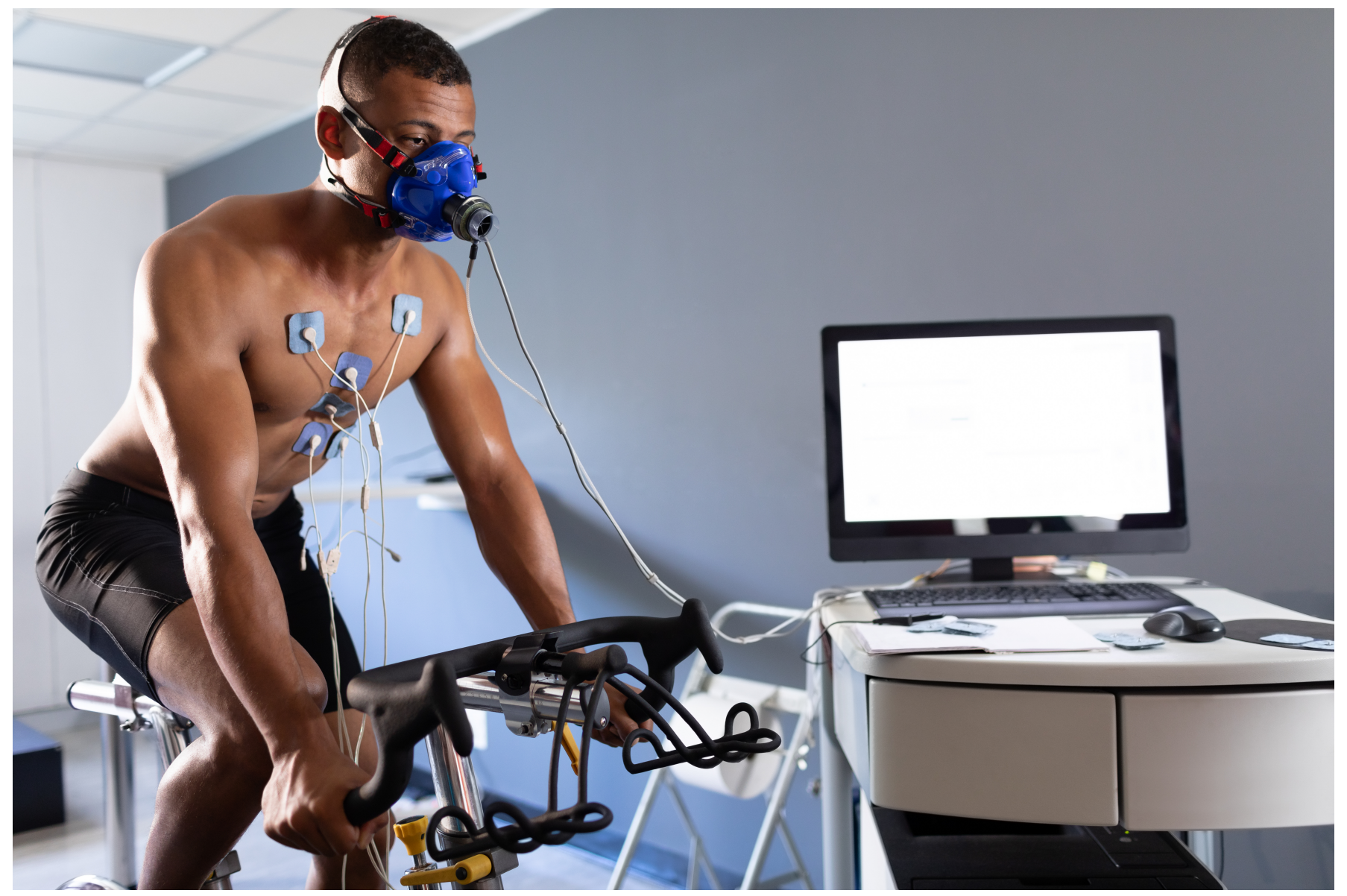

Mazaheri R, Tavana B, Halabchi F

Department of Sports \& Exercise Medicine, Faculty of Medicine, Tehran University of Medical Sciences, Tehran, Iran

\section{Abstract}

Cardiopulmonary exercise testing (CPET) is recommended in pre-participation evaluation of athletes to measure their cardiorespiratory fitness and maximal exercise tolerance. It is used for the diagnosis of probable cardiovascular and pulmonary disease and for the investigation of possible risks in sports. In case of non-specific symptoms during exercise, which are frequent in athletes, CPET is useful in the evaluation of physiological responses of body organ systems to exercise. This case-based review 
demonstrate the potential of CPET in the assessment of fatigue and loss of performance in a competitive professional athlete.

\section{Zusammenfassung}

Herz-Lungen-Belastungstests (CPET) werden in der Beurteilung von Athleten vor der Aufnahme eines regelmässigen Trainings empfohlen, um ihre kardiorespiratorische Fitness und maximale Belastungstoleranz zu messen. Zudem wird die Untersuchung zur Diagnose von möglichen Herz-Kreislaufund Lungenerkrankungen sowie zur Untersuchung möglicher Risiken im Sport eingesetzt. Bei unspezifischen Symptomen während des Trainings, die bei Sportlern häufig auftreten, ist CPET bei der Bewertung der physiologischen Reaktionen von Körperorgansystemen auf körperliches Training hilfreich. Diese Fallstudie zeigt das Potenzial von CPET in der Beurteilung von Müdigkeit und Leistungsverlust bei einem professionellen Leistungssportler auf.

\section{Introduction}

Cardiopulmonary exercise testing (CPET) is a well-accepted method to measure cardiorespiratory fitness and prescribe the precise intensity of exercise in a highly individualized manner [1] especially in elite athletes. The growing volume of evidence supports the use of CPET in pre-participation evaluation of athletes and diagnosis of possible cardiovascular and/or pulmonary impairments in the presence of early fatigue and exercise intolerance [2,3]. As CPET provides an integrated assessment of multiple organ systems during exercise [4], it might be used to evaluate dynamic physiological impairments to exercise. Competitive athletes commonly intensify their training load before important tournaments and they might mistakenly have inadequate recovery in an attempt to enhance performance. As a result, they may experience some feelings of early fatigue or decreased performance especially in response to an intense training session that is stressful psychologically and could shift them towards performance enhancing drugs. Cardiopulmonary exercise testing is helpful in the assessment of these symptoms and could potentially differentiate some altered physiological responses to exercise with disease states.

In this case-based review, a complete workup of an athlete with early fatigue and loss of performance will be discussed with special focus on his CPET results and treatment strategy. The main aim of this paper is to put forward and expand the potential applications of CPET in the evaluation of physiologic responses to exercise in the athletic population.

\section{Case presentation}

A 28 years old male professional kickboxer presented with early fatigue and performance decline over the past 4 weeks. He had more than 11 years professional carrier in kickboxing with multiple championships in different competitions. Preparing for a very important international tournament at next month, he had an intense training program with a proper balanced diet in the last few months.

He complained of early muscular fatigue like his previous experiences of lactate accumulation and loss of performance without any other symptoms. He had a negative past history and family history of certain diseases with normal primary physical examination at rest. In other words, he had just an elevated rating of perceived exertion (RPE) and poor performance in his training sessions, recently. 


\section{Work-up}

There is a long list of differential diagnoses for fatigue and as well, the work-up of a professional athlete with fatigue could be challenging. Many diseases including cardiac, pulmonary, metabolic, endocrine, infectious and hematologic disorders along with psychological problems are mentioned [5]. Overtraining syndrome is another cause of fatigue in athletes and the definitive diagnosis always requires the exclusion of organic diseases with several confounding factors [6].

Some laboratory tests to diagnose specific diseases are listed in table 1. Laboratory tests are used to confirm some hematologic, infectious and metabolic diseases or to assess endocrine causes of fatigue [5]. Laboratory tests including hematology, biochemistry, hormone and urine analyses were unremarkable. The majority of the blood parameters (e.g. glucose, blood count, urea, creatinine, ferritin, liver enzymes, erythrocyte sedimentation rate, C-reactive protein, creatine kinase, sodium and potassium) are not able to detect the precise etiology of fatigue but they are helpful for the assessment of the health status of the athlete and useful in the exclusion diagnosis [6]. 


\begin{tabular}{|c|c|c|}
\hline Test & Result & $\begin{array}{l}\text { Reference } \\
\text { Range }\end{array}$ \\
\hline \multicolumn{3}{|l|}{ Hematology } \\
\hline White blood cell (×1000/mic) & 6.5 & $4,4-11$ \\
\hline - Neutrophils [\%] & 67.5 & \\
\hline - Lymphocyte (\%) & 26.9 & \\
\hline$-\operatorname{Mix}(\%)$ & 5.6 & \\
\hline Red blood cell (xmillion/m) & 4.79 & $4.5-5.9$ \\
\hline Hemoglobin (g/dL) & 14.1 & $14-17.5$ \\
\hline Hematocrite $[\%]$ & 42.5 & $41.5-50.4$ \\
\hline Mean Corpuscular Volume [fL] & 88.7 & $80-96$ \\
\hline Mean Cell Hemoglobine (pg) & 29.4 & $27.5-33.2$ \\
\hline Platelets (×1000/mic) & 272 & $150-450$ \\
\hline Red cell Distribution Width (\%) & 13.4 & $11.6-14.6$ \\
\hline $\mathrm{ESR}(\mathrm{mm} / \mathrm{hr}]$ & 6 & $<15$ \\
\hline \multicolumn{3}{|l|}{ Biochemistry } \\
\hline Fasting Blood Sugar (mg/dl) & 85 & $70-110$ \\
\hline Uric Acid (mg/dl) & 5.4 & $3.6-8.2$ \\
\hline Triglycerides (mg/dl) & 132 & $10-190$ \\
\hline Cholesterol (mg/dl) & 255 & $130-200$ \\
\hline - LDL-chol (mg/dl) & 144 & \\
\hline - HDL-chol [mg/dl] & 74 & \\
\hline Creatinine (mg/dl) & 1.2 & $0.7-1.4$ \\
\hline Sodium (mEq/L) & 138 & $135-145$ \\
\hline Potassium (mEq/L) & 3.9 & $3.8-5$ \\
\hline Calcium (mg/dl) & 9.7 & $8.6-10.3$ \\
\hline SGOT (AST) (IU/L) & 42 & Up to 37 \\
\hline SGPT (ALT) (IU/L) & 51 & Up to 41 \\
\hline Alkaline phosphatase (IU/L) & 192 & $80-306$ \\
\hline LDH (IU/L) & 348 & $5-480$ \\
\hline \multicolumn{3}{|l|}{ Hormone Analysis } \\
\hline Testosterone (ng/mL) & 3.2 & $2.8-8.0$ \\
\hline Cortisol 8 am (ng/mL) & 83.2 & $54.94-287.56$ \\
\hline TSH [miclU/ml] & 1.49 & $0.27-4.2$ \\
\hline T4 (micg/dL) & 4.98 & $5.52-12.6$ \\
\hline PTH $(p g / m L)$ & 18 & $15-65$ \\
\hline $25 \mathrm{OH}$ Vitamin D3 (ng/mL) & 38.8 & $29-100$ \\
\hline
\end{tabular}



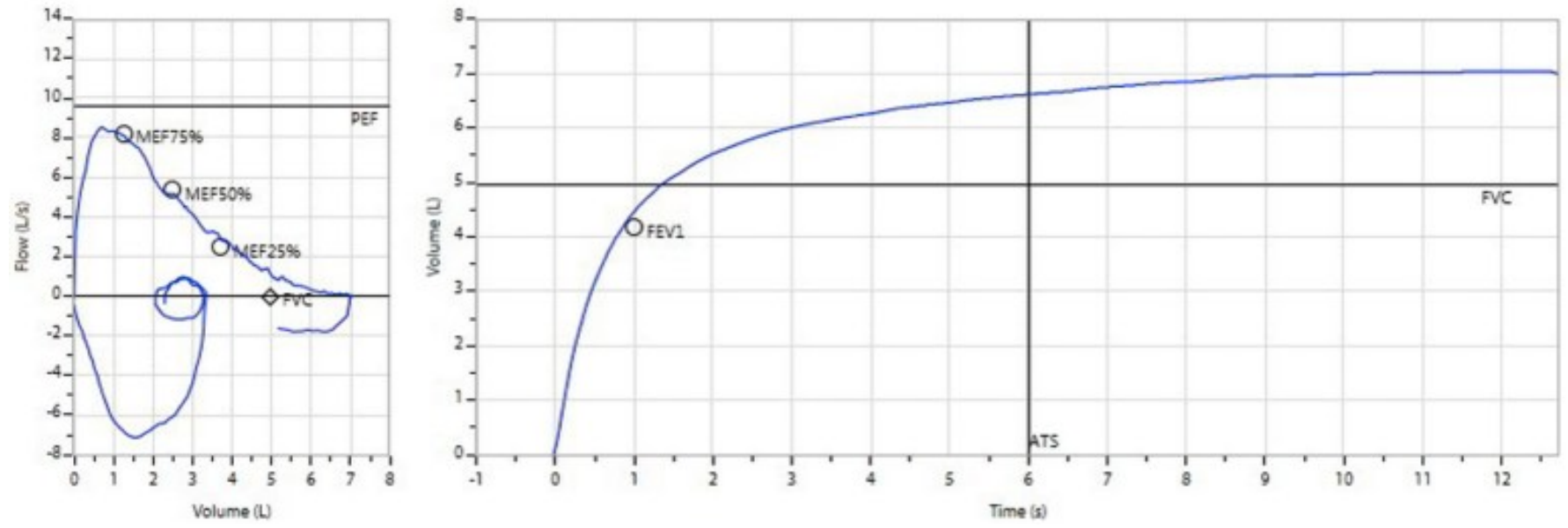

Figure 1: Resting pulmonary function test

Pulmonary diseases can have a remarkable effect on exercise capacity [7] and athletic performance. Pulmonary function testing is used to measure baseline lung function, detect pulmonary disease and evaluate respiratory impairments. Spirometry results of the athlete are depicted in figure 1 and table 2 . Cough, shortness of breath and chest tightness are the main symptoms of pulmonary diseases but exercise related fatigue and decreased performance might be among the complaints of these athletes (5).

\begin{tabular}{|l|c|c|c|}
\hline Parameters & Meas. & Pred & \% Pred \\
\hline FVC (L) & 7.08 & 4.95 & 143 \\
\hline FEV1 (L) & 4.48 & 4.18 & 107 \\
\hline FEV1/FVC & 63.40 & 82.20 & 77 \\
\hline PEF (L/s) & 8.56 & 9.63 & 89 \\
\hline
\end{tabular}

Table 2: Spirometry results from a maximally forced expiratory effort

In general, the pulmonary function test was within normal range except the FEV1/FVC of 63.4\%, which is below the normal limits. It might be due to a mild obstruction disproportionate to the athlete's complaints.

\section{Cardiopulmonary Exercise Test}

Cardiopulmonary exercise testing provides valuable information regarding gas exchange at rest, during exercise and recovery and adds breath-by-breath measures of oxygen uptake (VO2), carbon dioxide output 
(VCO2) and minute ventilation (VE) to the standard variables obtainable from conventional exercise testing [8,9]. Important parameters provided by CPET are peak oxygen uptake, ventilatory threshold, respiratory exchange ratio, oxygen pulse, minute ventilation to carbon dioxide production slope and partial pressure of end-tidal carbon dioxide. Depending on the clinical setting and the indication of CPET in the individual subject, such as in the evaluation of exercise intolerance, the relevant parameters have to be considered.

The resting electrocardiography (ECG) of the athlete at the beginning of the exercise test is shown on figure 2 and the CPET parameters are summarized on table 3.

As it is evident, the resting ECG shows complete right bundle branch block (RBBB) pattern along with right axis deviation of more than 120 degrees. According to the international criteria for ECG interpretation in athletes, two borderline findings warrant additional investigation for pathologic cardiovascular disorders associated with sudden cardiac death in athletes [10]. In this regard, echocardiogram is recommended to find potential myocardial disease. Echocardiography of the athlete was normal and compatible with athlete's heart with mild to moderate left ventricular hypertrophy and high normal right ventricular size and function.

Cardiorespiratory fitness of the athlete expressed by peak VO2 is almost $115 \%$ of the predicted value, which is above the normal level and is expected from a professional athlete especially during an intense training period before the tournament. At first glance, all the other variables are within the normal range based on the EACPR/AHA joint scientific statement for CPET assessment [1]. The line and scatter charts of the CPET are shown on figure 3.

The clinical specific conditions, test indication and population under investigation are important components for CPET interpretation based on current scientific evidence. Closer look at CPET data reveals that the ventilatory threshold (VT) of the athlete is at 53.3\% of peak VO2 that is normal in healthy untrained subjects but too low for a competitive professional athlete.

There is controversy surrounding the mechanisms responsible for the VT nonetheless, it coincides with the lactate threshold during exercise testing. Ventilatory threshold typically corresponds to $55 \pm 8 \%$ of the peak VO2 in healthy untrained individuals. However, it generally occurs at a higher percentage of exercise capacity (i.e. 70-90\%) in physically trained athletes [11]. The low VT level in our athlete means that exercise intensities of more than just $53.3 \%$ of his peak VO2 induce a significant increase in blood lactate and might cause muscle fatigue. 


\begin{tabular}{|c|c|c|}
\hline Variable & value & reference \\
\hline $\begin{array}{l}\text { Peak VO } \\
\text { (ml/kg/min) }\end{array}$ & 51.72 & 45.02 \\
\hline $\begin{array}{l}\text { Percent predicted } \\
\text { peak } \mathrm{VO}_{2}(\%)\end{array}$ & 114.88 & \\
\hline $\begin{array}{l}\text { Ventilatory } \\
\text { threshold (VT) } \\
\text { (ml/kg/min) }\end{array}$ & 27.57 & \\
\hline $\mathrm{VT}\left(\%\right.$ of $\left.\mathrm{VO}_{2} \max \right)$ & 53.3 & $\approx 50-65$ \\
\hline $\begin{array}{l}\text { Peak respiratory } \\
\text { exchange ratio }\end{array}$ & 1.03 & $\geq 1.1$ \\
\hline VE/ $/ \mathrm{VCO}_{2}$ slope & 27.8 & $<30$ \\
\hline $\begin{array}{l}\mathrm{P}_{\mathrm{ET}} \mathrm{CO}_{2} \text { rest } \\
(\mathrm{mmHg})\end{array}$ & 37 & $36-42$ \\
\hline $\begin{array}{l}\mathrm{P}_{\mathrm{ET}} \mathrm{CO}_{2} \text { at } \mathrm{VT} \text { level } \\
(\mathrm{mmHg})\end{array}$ & 45 & Increases 3-8 \\
\hline $\mathrm{VE} / \mathrm{VO}_{2}$ at peak & 29.6 & $\leq 40$ \\
\hline VE/MVV & 0.64 & $\leq 0.8$ \\
\hline $\begin{array}{l}\mathrm{O}_{2} \text { pulse max } \\
\text { (mL/beat) }\end{array}$ & 22.02 & 17.77 \\
\hline METs max & 14.77 & \\
\hline $\begin{array}{l}\text { HR max } \\
\text { (beat/min) }\end{array}$ & 178 & 192 \\
\hline $\begin{array}{l}\text { HR recovery at } \\
1 \mathrm{~min} \text { (beat } / \mathrm{min} \text { ) }\end{array}$ & 39 & $>12$ \\
\hline $\begin{array}{l}\text { Blood Pressure } \\
\max (\mathrm{mmHg})\end{array}$ & $222 / 94$ & $\mathrm{SBP} \sim 210$ \\
\hline
\end{tabular}




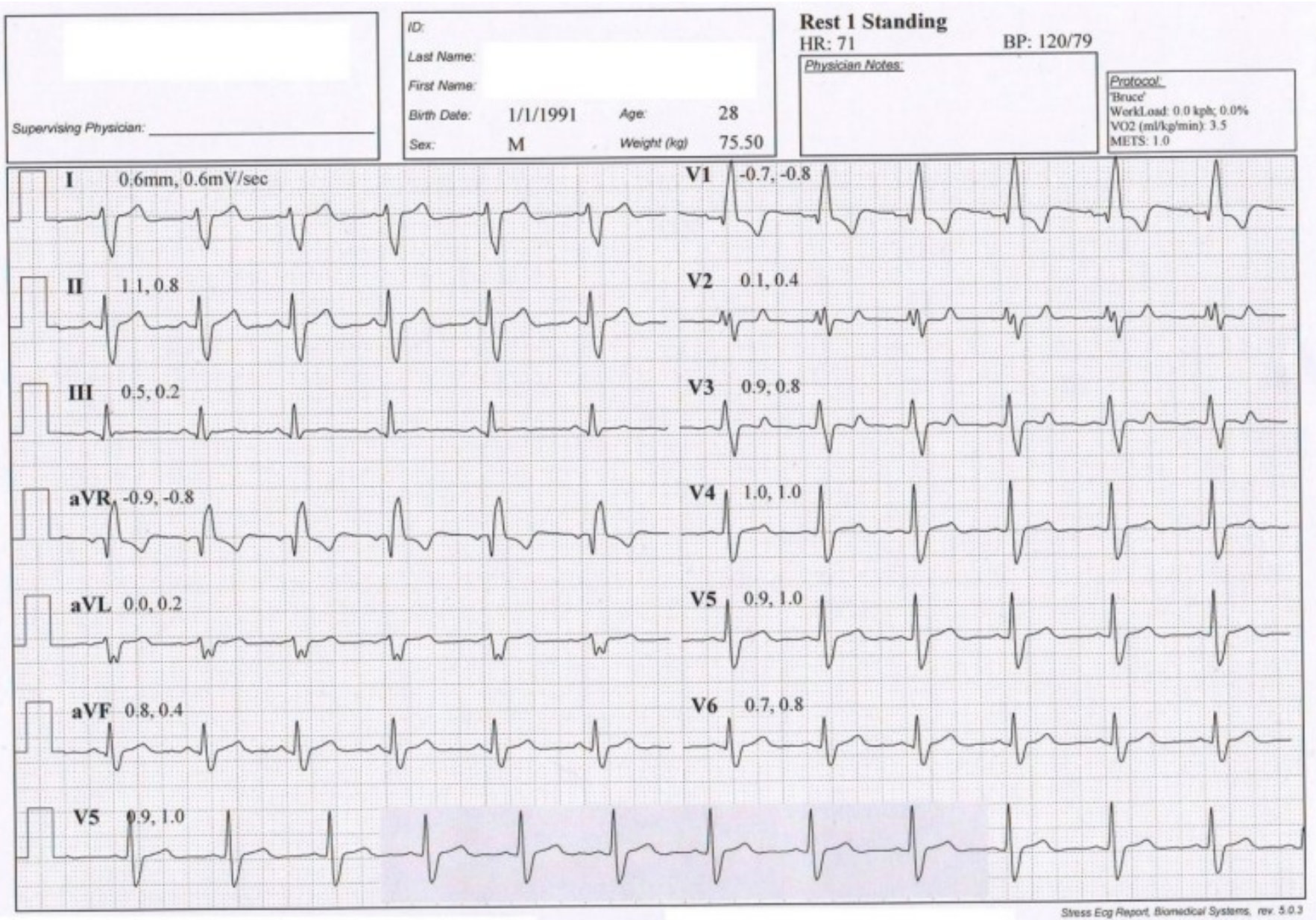

Figure 2: Resting electrocardiography

\section{Discussion}

This case-based review remarks the application of CPET in athletes and emphasizes the importance of special considerations in its interpretation in an athletic population. As a well-accepted procedure used for the investigation of cardiac and pulmonary disorders, CPET is expounded on the response of particular functional indices, such as the peak VO2 and VT to incremental exercise. Knowledge of the normal responses is necessary for the precise interpretation, but the reference values have to be considered with respect to sex, age, body features and physical activity status [12]. Athletes with intense conditioning represent substantial cardiopulmonary adaptations to exercise [13] and need distinct attention concerning their physiological assessments.

Investigations to find the exact etiology of fatigue and decreased performance in athletes are challenging 
and despite great interest in the topic of fatigue, surprisingly little is known about its impact on performance [14]. Managing fatigue in athletes is important, because it monitors the athlete's load in terms of the measures which offer insights whether they are adapting positively or negatively to the stresses of training and competition [15]. There are various maximal performance assessment tests to quantify the rate of recovery and performance in athletes.

Optimizing the recovery-stress cycle is crucial for desirable performance in elite athletes and it is recommended that this cycle is continuously monitored during the training process [16]. Excessive volume or intensity of exercise beyond the limits of the athlete's physical ability results in decreased sport-specific athletic performance. In this state, he or she can be considered overtrained or overreached [17]. Overreaching (OR) and overtraining (OT) are on the same spectrum that can lead to overtraining syndrome (OTS). Functional OR can be affected with positive physiological adaptations and performance improvements after short-term recovery (3 to 14 days) [18]. Non-functional OR and OT are intricate and need longer recovery period.

Blood lactate measurements can be dependent on the training status of athletes. Muscle and liver glycogen status are also other important factors [6]. Lactic acid is introduced as a fatigue agent and blood lactate measurements help to interpret an athlete's resistance to fatigue during high intensity exercise. Accumulation of lactate in working muscles causes inhibition of contractile processes and results in diminished exercise performance [19]. As previously discussed in this paper, ventilatory threshold corresponds with the lactate threshold, so it might be used as a surrogate for blood lactate measurements in the assessment of fatigue and reduced performance in athletes.

The ventilatory threshold of the mentioned athlete in this paper was at $53.3 \%$ of peak VO2 which is too low for professional competitive athletes. It means that above this level of exercise, blood lactate is rapidly accumulated which reflects increases in muscle acidity and rapid glycogen depletion through anaerobic glycolysis. These factors strongly contribute to fatigue and reduced exercise performance [19].

Finally, after about 3 weeks of rest and recovery, the athlete went to the international kickboxing tournament and won the competition. In justifying, we can hypothesize that intense training in the preparation phase of the athlete resulted in some levels of OR with early fatigue and reduced performance. Decreased VT, which is not expected from this professional athlete might be the result of OR state with improved performance after recovery. Cardiopulmonary exercise testing is recommended for future research purposes in the evaluation of such athletes. 


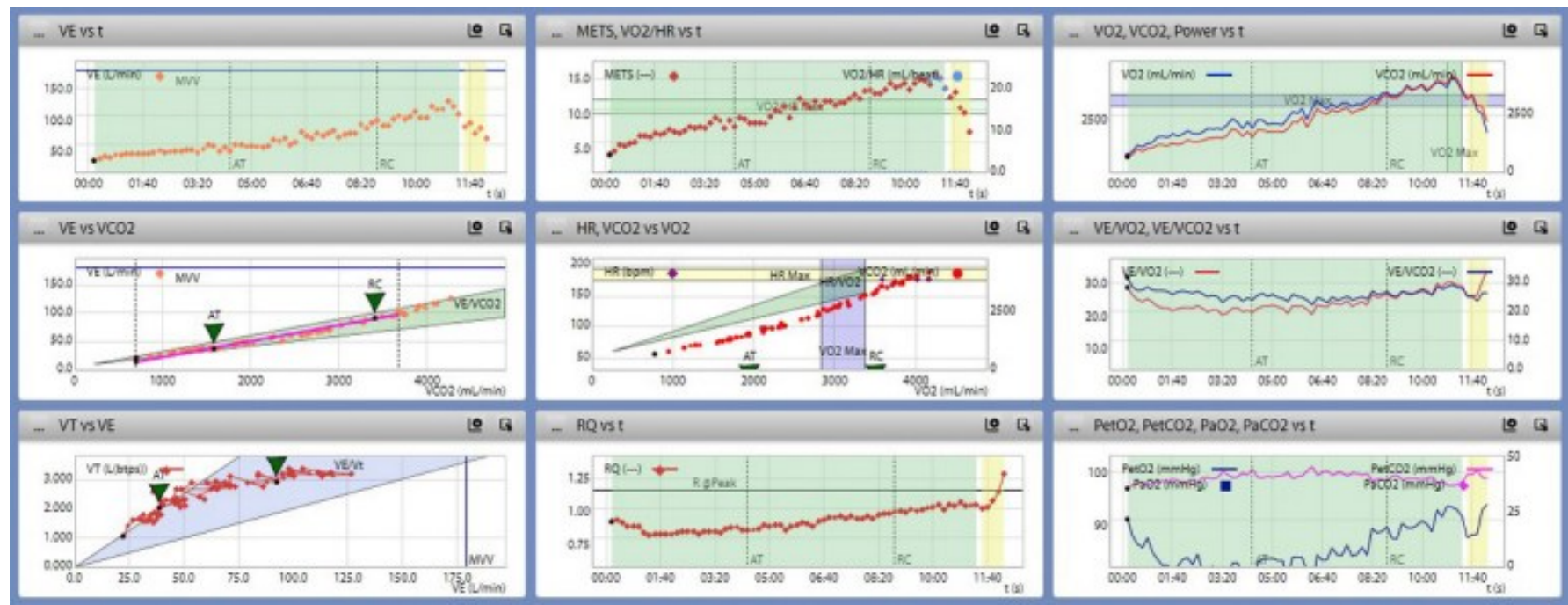

Figure 3: Line and scatter charts of the CPET

\section{Conclusion and summary}

- Cardiopulmonary exercise testing is used for the diagnosis and prognosis of cardiac and pulmonary disease in athletes and investigation of possible risks in sports.

- Additionally, it is a well-accepted tool for assessment of the physiological responses of body organ systems to training and exercise.

- Athletes with non-specific symptoms during exercise could be evaluated well with CPET.

- Interpretation of the CPET results in athletic population requires special attention, because the expected values are different from healthy untrained individuals.

\section{First Author}

Associate Prof. Dr. med. Reza Mazaheri

Email:mazaheri_md@tums.ac.ir

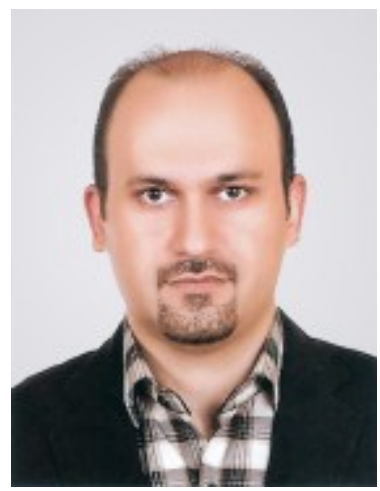




\section{Corresponding author}

Prof. Dr. med. Farzin Halabchi

Email: fhalabchi@tums.ac.ir

\section{References}

1. Guazzi M, Adams V, Conraads V, Halle M, Mezzani A, Vanhees L, et al. EACPR/AHA Joint Scientific Statement. Clinical recommendations for cardiopulmonary exercise testing data assessment in specific patient populations. European heart journal. 2012;33(23):2917-27.

2. Nelson N, Asplund CA. Exercise Testing: Who, When, and Why? PM\&R. 2016;8:S16-S23.

3. Lollgen H, Leyk D. Exercise Testing in Sports Medicine. Deutsches Ärzteblatt international. 2018;115(24):409-16.

4. Albouaini K, Egred M, Alahmar A, Wright DJ. Cardiopulmonary exercise testing and its application. Postgraduate medical journal. 2007;83(985):675-82.

5. Moeller JL. The athlete with fatigue. Current sports medicine reports. 2004;3(6):304-9.

6. Meeusen R, Duclos M, Foster C, Fry A, Gleeson M, Nieman D, et al. Prevention, diagnosis, and treatment of the overtraining syndrome: joint consensus statement of the European College of Sport Science and the American College of Sports Medicine. Medicine and science in sports and exercise. 2013;45(1):186-205.

7. Ament W, Verkerke GJ. Exercise and fatigue. Sports medicine. 2009;39(5):389-422.

8. Balady GJ, Arena R, Sietsema K, Myers J, Coke L, Fletcher GF, et al. Clinician's Guide to cardiopulmonary exercise testing in adults: a scientific statement from the American Heart Association. Circulation. 2010;122(2):191-225.

9. Mezzani A. Cardiopulmonary Exercise Testing: Basics of Methodology and Measurements. Annals of the American Thoracic Society. 2017;14(Supplement_1):S3-S11.

10. Drezner JA, Sharma S, Baggish A, Papadakis M, Wilson MG, Prutkin JM, et al. International criteria for electrocardiographic interpretation in athletes: Consensus statement. British journal of sports medicine. 2017;51(9):704-31.

11. Medicine ACS, Swain DP, Brawner CA. ACSM’s Resource Manual for Guidelines for Exercise Testing and Prescription: Wolters Kluwer Health/Lippincott Williams \& Wilkins; 2012.

12. Koch B, Schaper C, Ittermann T, Spielhagen T, Dorr M, Volzke H, et al. Reference values for cardiopulmonary exercise testing in healthy volunteers: the SHIP study. The European respiratory journal. 2009;33(2):389-97.

13. Baggish AL, Wood MJ. Athlete's heart and cardiovascular care of the athlete: scientific and clinical update. Circulation. 2011;123(23):2723-35. 
14. Enoka RM, Duchateau J. Translating Fatigue to Human Performance. Medicine and science in sports and exercise. 2016;48(11):2228-38.

15. Thorpe RT, Atkinson G, Drust B, Gregson W. Monitoring Fatigue Status in Elite Team-Sport Athletes: Implications for Practice. International journal of sports physiology and performance. 2017;12(Suppl 2):S227-S34.

16. Kellmann M. Preventing overtraining in athletes in high-intensity sports and stress/recovery monitoring. Scandinavian journal of medicine \& science in sports. 2010;20 Suppl 2:95-102.

17. Kreher JB. Diagnosis and prevention of overtraining syndrome: an opinion on education strategies. Open access journal of sports medicine. 2016;7:115-22.

18. Carfagno DG, Hendrix JC, 3rd. Overtraining syndrome in the athlete: current clinical practice. Current sports medicine reports. 2014;13(1):45-51.

19. Theofilidis G, Bogdanis GC, Koutedakis Y, Karatzaferi C. Monitoring Exercise-Induced Muscle Fatigue and Adaptations: Making Sense of Popular or Emerging Indices and Biomarkers. Sports. 2018;6(4). 